\title{
Diet composition and feeding habits of Oreochromis niloticus (Linnaeus, 1758) in Lake Shala, Ethiopia
}

\author{
Solomon Wagaw ${ }^{1,2, *}$, Seyoum Mengistou ${ }^{2}$, Abebe Getahun ${ }^{2}$ \\ ${ }^{1}$ Department of Biology, Wolkite University, Wolkite, Ethiopia \\ ${ }^{2}$ Department of Zoological Sciences, Addis Ababa University, Addis Ababa, Ethiopia
}

\begin{abstract}
The present study was carried out to investigate the food and feeding habits of Oreochromis niloticus in Lake Shala to manage this species in this high Soda Lake. Stomachs of 226 fish (65.9\%) had different food items, while those of 117 fish (34.1\%) were empty. Phytoplankton was the dominant food categories occurring in $90.3 \%$ of the stomachs estimated and contributed $75.5 \%$ of the total volume. Bacillariophyceae (Nitzschia, Anomoeoneis, Navicula and Melosira) were identified as the most desired phytoplankton item. The prey items of $O$. niloticus differed among size classes (ANOVA, $p<0.05$ ). The main prey items were zooplankton by the smaller-size class, and phytoplankton in fish of the larger-size class. Seasonal variation in the diet composition was evident $(t$-test, $p<0.05)$ and zooplankton, chironomids, nematodes, fish scales and detritus were important during the wet season, while phytoplankton predominates during the dry season. This study concludes that $O$. niloticus had a phytoplanktivores feeding mainly on phytoplankton and their feeding habits influenced by season and fish size in Lake Shala.
\end{abstract}

Keywords: Bacillariophyceae, Feeding habits, Lake Shala, Oreochromis niloticus, Phytoplanktivores

\section{Introduction}

Description of the food and feeding habits of fish are important for the identification of the trophic relationships present in aquatic ecosystems, identifying feeding composition, structure and stability of food webs (Hussian et al., 2019; Oso et al., 2006 ). Of course this will improves the understanding of their distribution, abundance, growth, and productivity (Hussian et al., 2019; Kariman et al., 2009). Moreover, investigating the food and feeding habits of the commercial fish species is a very important concern since it establishes the basis for the development of effective fisheries management programs (Defaye, 1988; Engdaw et al., 2013; Teferi et al., 2000).

The Nile tilapia, Oreochromis niloticus (Linnaeus, 1758), is one of the most widespread and important species in tropical freshwater (Oso et al., 2006; Teferi et al., 2000). Oreochromis niloticus can be found in most types of freshwater habitats, such as rivers, streams, lakes, reservoirs and ponds (Golubtsov et al.,

Received: Jun 24, 2021 Revised: Oct 28, 2021 Accepted: Nov 16, 2021

${ }^{5}$ This work is the modification of the first author's Ph.D. dissertation.

${ }^{\star}$ Corresponding author: Solomon Wagaw

Department of Biology, Wolkite University, Wolkite, Ethiopia

Tel: +251-912826830, E-mail: wagawsolomon2@gmail.com

This is an Open Access article distributed under the terms of the Creative Commons Attribution Non-Commercial License (http://creativecommons.org/licenses/by$\mathrm{nc} / 4.0 /$ ) which permits unrestricted non-commercial use, distribution, and reproduction in any medium, provided the original work is properly cited.

Copyright $\odot 2022$ The Korean Society of Fisheries and Aquatic Science 
2002). The species prefer water temperatures between $16^{\circ} \mathrm{C}$ and $29^{\circ} \mathrm{C}$ (Kavembe et al., 2016; Nyakuni, 2009). In Ethiopia, it is widely distributed in the lakes, rivers, reservoirs and swamps with a significant economic and ecological contribution (Golubtsov et al., 2002; Temesgen, 2017). However, some economically driven developments in and around the lakes continue to exert considerable pressure on saline lake fish populations (Gebremariam, 2002; Kavembe et al., 2016; Reaugh-Flower, 2011). The best example of this is Lake Abijata, in which the lake was full of O. niloticus (Reaugh-Flower, 2011). However, Abdi (1993) noted the disappearance of O. niloticus from Lake Abijata after the establishment of the soda ash factory. At the same time a number of piscivorous birds such as the Great White Pelican (Pelecanus onocrotalus roseus) and cormorant have been migrating to adjacent lakes.

Several authors have studied the food and feeding habits of O. niloticus in different Ethiopian water bodies (Assefa \& Getahun, 2015; Engdaw et al., 2013; Teferi et al., 2000). These studies mainly focused on freshwater O. niloticus. Research on the Soda Lake of fish species is limited only to the description of diversity (Getahun, 2001). The fish fauna of Lake Shala was reported by Golubtsov et al. (2002) and Klemperer \& Cash (2007); the latter reported only Aplocheilichthys which was retrieved after seismic detonations in the lake. There was no report of tilapia or other fish in the lake, and it was presumed that tilapia had disappeared due to osmotic stress and other factors from the lake. It was a surprise for this study to 'locate' a tilapia stock from the southern river mouth of the freshwater Gidu River. Therefore, this study was carried out to investigate the diet composition and feeding habits of Oreochromis niloticus inhabited Shala Lake, as part of a general study on the biology and ecology of the fish.

\section{Materials and Methods}

\section{Description of the study area}

Lake Shala lies between $7^{\circ} 24^{\prime}-7^{\circ} 33^{\prime} \mathrm{N}$ and $38^{\circ} 23^{\prime}-38^{\circ} 39^{\prime} \mathrm{E}$ at altitudes of approximately 1,558 $\mathrm{m}$ within the Abijata-Shala Lakes National Park (Fig. 1). The lake is a volcano-tectonic lake (Le Turdu et al., 1999), deep (max. $266 \mathrm{~m}$ ) and large (329 $\left.\mathrm{km}^{2}\right)$, with a vast catchment area $\left(3,920 \mathrm{~km}^{2}\right)$ (Baxter, 2002; Von Damm \& Edmond, 1984). The lake region is characterized by a high evaporation rate that exceeds the mean annual rainfall (Ayenew \& Legesse, 2007). Climate of the Ziway-Shala region is mainly characterized by alternating wet and dry seasons fol- lowing the annual movements of the Intertropical Convergence Zone (ITCZ) (Von Damm \& Edmond, 1984), the dry seasons from October to February and rainy seasons March to September. The rainy season is characterized by a bimodal rainfall pattern, with a minor rainy period extending from March to May and the major rainy period from June to September.

Lake Shala receives its water from the Adabat and Gidu River (Baumann et al., 1975; Baxter, 2002). The lake is also surrounded by numerous hot springs, of varying salinity, temperature, size and discharge rate, which feed the lake (Baxter, 2002). Lake Shala is characterized by a high surface water temperature, $\mathrm{pH}$, saline-alkaline conditions and a high phosphate content, but with very low nitrogen levels (Kebede et al., 1994; Ogato, 2015). Despite this hostile nature of the environment, Lake Shala supports phytoplankton, dominated by diatoms (Kebede et al., 1994). Lake Shala also supports sparse zooplankton community and dominated by rotifers including Brachionus dimidiatus, B. pliciatilis, Hexarthra spp, and Copepods (Cylopoids and Harpacticoids). The benthic macroinvertebrate community of the lake comprises Tubificidae, Ostracoda and Chironomidae (Tudorancea et al., 1988). The lake also known by an outstanding avifauna diversity, mainly Pelicans and Lesser Flamingos, inhabiting the lake and its volcanic island. The cichlid O. niloticus (Golubtsov et al., 2002) and Aplocheilichthys sp. (Klemperer \& Cash, 2007) being reported for the lake.

\section{Field fish sampling and morphometric measurement}

Samples of $O$. niloticus were collected monthly between January and December 2018 using experimental gill net at a fixed site throughout the study (Fig. 1). Gillnets had stretched mesh sizes of 4-14 cm with a panel length of $50 \mathrm{~m}$ and a width of 1.5-2.0 $\mathrm{m}$ per mesh size. The nets were set parallel to the shoreline in the afternoon (about 05:00 pm) and lifted in the following morning (about 7:00 am). Immediately after capture, total length (TL) and total weight (TW) of each specimen were measured to the nearest $0.1 \mathrm{~cm}$ and $1.0 \mathrm{~g}$, respectively. Each specimen was dissected to determine sex, stomach containing food was preserved in 5\% formaldehyde solution and transported to Addis Ababa University for further laboratory analysis.

\section{Stomach content analysis}

The preserved stomach content of $O$. niloticus was transferred into a petri dish and analyzed using a modified point method according to Hyslop (Hyslop, 1980). Food items were examined under a dissecting LEICA S8 APO and a compound LEICA 

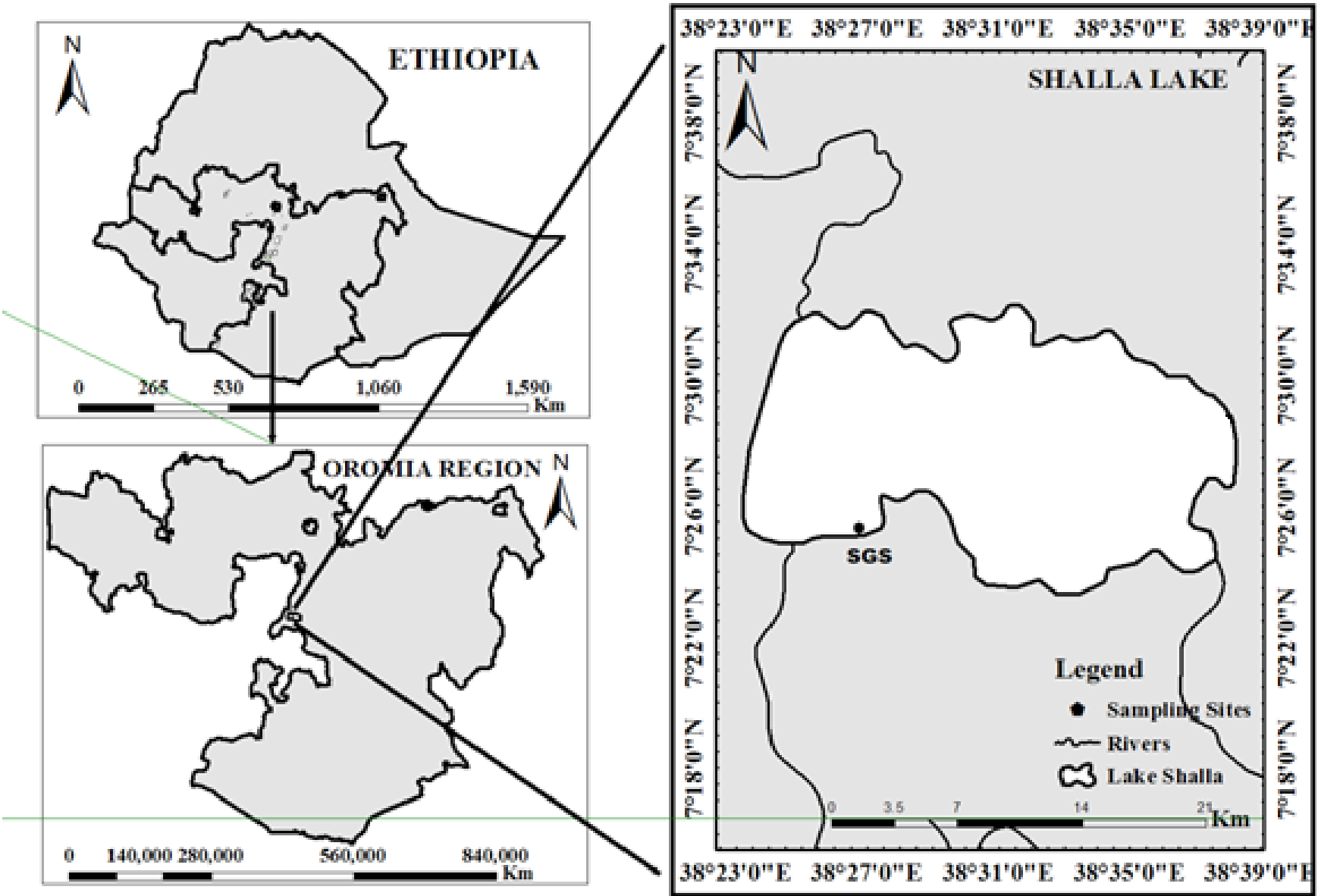

Fig. 1. Map of Lake Shala showing sampling site. SGS, Shala Gike Shore.

DME microscope $(100 \times$ to $400 \times$ magnification). The food items were identified to the lowest possible taxonomic level by using description, illustrations and keys in the literature (Bellinger \& Sigee, 2010; Defaye, 1988; Gasse, 1983). Each category was assigned several points proportional to the estimated contribution.

The contribution of each prey functional category to the overall stomach contents was assessed using two indices: percent frequency of occurrence (\%Q) and percent composition by volume (\%V) (Hyslop, 1980). In the frequency of occurrence method, the occurrence of food items was expressed as the percentage of the total number of stomachs. \%Q provides information on the proportion of fish stomachs containing a particular prey item despite amount (Hyslop, 1980). The percentage volume contribution of each food item is visually assessed relative to all of the food items present in the gut. Volumetric contribution $(\mathrm{mL})$ and frequency of occurrence were also used to compute the index of food preponderance (IOPa) and geometric importance of index (GIIi).

For the assessment of the importance of each prey category, the index of preponderance (IOPa) (Sreeraj et al., 2006; Tomojiri et al., 2019) was calculated as:

$$
\operatorname{IOPa}(I)=\frac{Q i \times \% V i}{\sum_{i=1}^{S}(Q i+\% V i)}
$$

Where $S$ is the number of prey types, $Q i$ is the frequency of occurrence of species $i$ and $\% V i$ is the percent composition by volume of species $i$. To facilitate comparisons among species, IOPa was converted into percent IOPa (\%IOPa).

In order to evaluate the relative importance of food items and species-level dietary variations, Geometric Index of Importance (GIIi) (Assis, 1996) was computed as. 


$$
G I I i=\frac{\left(\sum R M P Q i\right)}{(\sqrt{n})}
$$

Where, $R M P Q i=$ percentage of volume and frequency of occurrence (as a percentage of total occurrences) and $n=$ total number of RMPQ parameters used to generate GIIi. GIIi index treats each dietary metric equally and some prey items were better represented by $\% \mathrm{~N}$ (e.g., smaller but countable prey) whereas others were better represented by $\% \mathrm{~V}$ (e.g., fish and other larger prey).

Phytoplankton preference index (PPI) was determined using percentage frequency of occurrence through the following equation described by Chrisafi et al. (2007) and Hussian et al. (2019).

$$
P P I=\frac{Q P h i}{Q E P i} \times 100
$$

Where: $P P I=$ Phytoplankton preference index

$Q P h i=$ Number of stomachs with a specific phytoplankton species

$Q E P i=$ The number of non-empty stomachs from phytoplankton

The different values of this index, allow separation of phytoplankton preference to three categories as main diet, secondary and accidentally eaten phytoplankton species (Hussian et al., 2019).

\section{Estimation of seasonal and size based food habit relationship}

Seasonal and sized based dietary variations of $O$. niloticus in Lake Shala was studied based on the percent volumetric contribution, frequency of each food item, IOPa (Sreeraj et al., 2006; Tomojiri et al., 2019) and GIli indices within each length group and seasons (Assis, 1996). For studying seasonal and size based diet variation, fish were classified into five size classes (15-20, 20-25, 25-30 and > $30 \mathrm{~cm} \mathrm{TL}$ ) and two seasons (dry and wet seasons).

\section{Results}

\section{Diet composition of O. niloticus in Lake Shala}

A total number of $343 \mathrm{O}$. niloticus samples were caught during the period of this study. Stomachs of 226 fish (65.9\%) had different food items, while those of 117 fish (34.1\%) were empty.
The food of O. niloticus in Lake Shala consisted of different food items including phytoplankton, zooplankton, insect, detritus, nematodes and fish scales (Table 1). Out of these food items, phytoplankton constituted the bulk of the foods consumed while zooplankton were the intermediately consumed prey types. The remaining food items such as insect, detritus, nematodes and fish scales were rarely consumed food items. The percentage of geometric importance index value (\%GIIi) also showed that phytoplankton was the primarily consumed prey type (Fig. 2). According to this index, zooplankton constituted the next important prey in the diet of O. niloticus, whereas insect, detritus, nematodes and fish scales were occasionally consumed.

Table 1. Frequency of occurrence (Qi), volumetric contribution (Vi), and index of preponderance (IOP) of functional prey categories in the diet of Oreochromis niloticus ( $\mathbf{n}=226)$ in Lake Shala, Ethiopia

\begin{tabular}{lllllll}
\hline Food type & $\mathrm{Qi}$ & $\% \mathrm{Qi}$ & $\mathrm{Vi}$ & $\% \mathrm{Vi}$ & $\mathrm{IOP}$ & IOP\% \\
\hline Phytoplankton & 204 & 90.3 & 221.3 & 75.5 & 31.4 & 91.0 \\
Zooplankton & 87 & 38.5 & 42.5 & 14.5 & 2.6 & 7.5 \\
Insects & 27 & 11.9 & 14.9 & 5.1 & 0.3 & 0.8 \\
Nematodes & 24 & 10.6 & 2.4 & 0.8 & 0.04 & 0.1 \\
Fish scales & 18 & 8.0 & 4.6 & 1.6 & 0.06 & 0.2 \\
Detritus & 31 & 13.7 & 7.25 & 2.5 & 0.2 & 0.5 \\
\hline
\end{tabular}

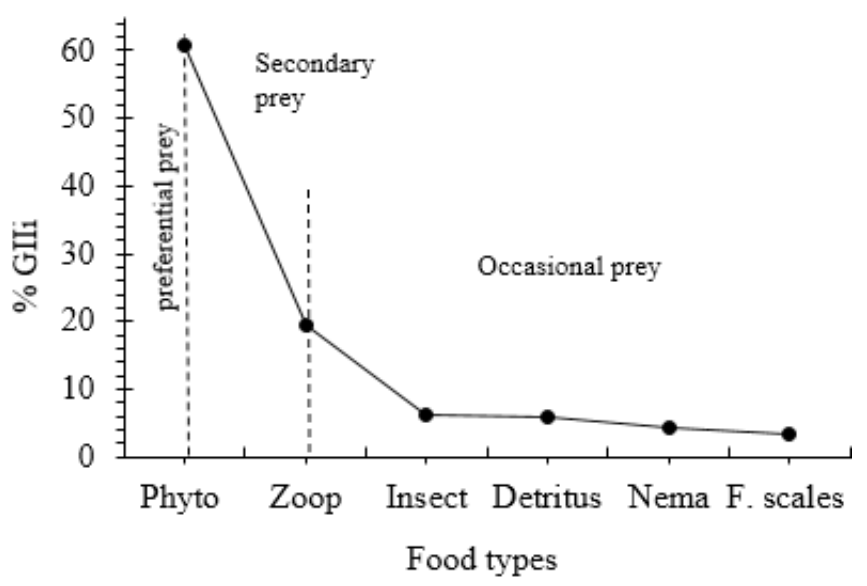

Fig. 2. Graphical presentation of percentage geometric index of importance (\%Glli) for food types of Oreochromis niloticus ( $\mathbf{n}=\mathbf{2 2 6}$ ) in Lake Shala. Phyto - Phytoplankton; Zoop -Zooplankton; Nema - Nematodes and F. scale - Fish scales; vertical lines separate the different degrees of preference of the food items. 
Phytoplankton occurred in $90.3 \%$ and constituted $75.5 \%$ of the total volume of food items. Based on the \%IOP index, phytoplankton also contributed about $91.0 \%$ of the diet. Among the phytoplanktons, Bacillariophyceae (Diatoms) such as Nitzschia, Anomoeoneis, Navicula and Melosira largely contributed to the highest preponderance index value $(91.3 \%)$ which occurred in $88.9 \%$ and accounted for $72.3 \%$ of the total volume of food items (Table 2). Moreover, the food selectivity index for phytoplankton species also indicated that O. niloticus in Lake Shala is more selective to Nitzschia, Anomoeoneis, Navicula and Melosira from Bacillariophyceae (Fig. 3). While Cyanophyceae (blue-green algae) such as Anabaena, Planktolyngbya, Phormidium and Spirulina were observed in $28.3 \%$ of the stomachs and constituted $3.2 \%$ of the total volume.

Zooplankton (Rotifers, Cyclopoids and Cladoceran) were the second important food items in the diet of $O$. niloticus that occurred in $38.5 \%$ of the stomach examined and constituted
$14.5 \%$ of the total volume of the food items consumed. The percentage index of preponderance $(\% \mathrm{IOP}=7.5 \%)$ and geometric importance index value $(\% \mathrm{GII}=19.4 \%)$ also showed that zooplankton were the most preferred food types. In the zooplankton food items, rotifers were the dominant group observed in $31.4 \%$ of the stomachs and accounted for $8.5 \%$ of the total volume of the food items consumed. The frequency of insect's occurrence was $11.9 \%$ and their volumetric contribution was $5.1 \%$ of the total volume of food items. Other food items identified were: nematodes, detritus and fish scale which occurred in $10.6 \%, 13.7 \%$, and $8.0 \%$ and accounted for $0.8 \%, 2.5 \%$, and $1.6 \%$.

\section{Variation of diet composition with fish size}

In O. niloticus there were significant differences in diet among size classes (ANOVA, $p<0.05$ ). The most important food source was zooplankton over the fish below $15 \mathrm{~cm}$ size classes

Table 2. Frequency of occurrence (Qi), volumetric contribution (Vi), index of preponderance (IOP) and percentage contribution of various food items of Oreochromis niloticus $(n=226)$ in Lake Shala

\begin{tabular}{|c|c|c|c|c|c|c|c|}
\hline Food items & & Qi & $\% Q i$ & $\mathrm{Vi}$ & $\% \mathrm{Vi}$ & $\mathrm{IOPa}$ & $10 P \%$ \\
\hline \multirow[t]{21}{*}{ Phytoplankton } & Bacillariophyceae & 201 & 88.9 & 211.9 & 72.3 & 24.9 & 91.3 \\
\hline & Nitzschia spp. & 198 & 87.6 & 89.04 & 30.4 & 4.7 & 17.8 \\
\hline & Navicula spp. & 176 & 77.9 & 27.1 & 9.3 & 1.3 & 14.4 \\
\hline & Melosira spp. & 121 & 53.5 & 15.4 & 5.3 & 0.5 & 9.8 \\
\hline & Achnanthes spp. & 36 & 15.9 & 2.6 & 0.9 & 0.02 & 2.9 \\
\hline & Anomoeoneis spp. & 181 & 80.1 & 36.7 & 12.5 & 1.8 & 15.1 \\
\hline & Cyclotella spp. & 52 & 23.0 & 7.1 & 2.4 & 0.1 & 4.2 \\
\hline & Epithemia spp. & 43 & 19.0 & 4.8 & 1.6 & 0.05 & 3.5 \\
\hline & Rhopalodia spp. & 71 & 31.4 & 13.4 & 4.6 & 0.3 & 6.0 \\
\hline & Frustulia spp. & 86 & 38.1 & 7.9 & 2.7 & 0.18 & 6.9 \\
\hline & Campylodiscus spp. & 41 & 18.1 & 1.91 & 0.7 & 0.02 & 3.2 \\
\hline & Amphora spp. & 36 & 15.9 & 1.4 & 0.5 & 0.01 & 2.8 \\
\hline & Surullia spp. & 28 & 12.4 & 0.81 & 0.3 & 0.006 & 2.2 \\
\hline & Flagillaria spp. & 31 & 13.7 & 0.94 & 0.3 & 0.008 & 2.4 \\
\hline & Cymbella spp. & 48 & 21.2 & 1.1 & 0.4 & 0.014 & 3.8 \\
\hline & Gomphonema spp. & 25 & 11.1 & 1.7 & 0.6 & 0.011 & 2.0 \\
\hline & Cyanophyceae & 64 & 28.3 & 9.4 & 3.2 & 0.4 & 1.3 \\
\hline & Anabaena spp. & 35 & 15.5 & 1.8 & 0.6 & 0.02 & 2.8 \\
\hline & Planktolyngbya spp. & 51 & 22.6 & 3.8 & 1.3 & 0.05 & 4.1 \\
\hline & Phormidium spp. & 46 & 20.4 & 3.1 & 1.1 & 0.04 & 3.7 \\
\hline & Spirulina spp. & 29 & 12.8 & 0.7 & 0.2 & 0.01 & 2.3 \\
\hline \multirow[t]{3}{*}{ Zooplankton } & Rotifera & 71 & 31.4 & 24.8 & 8.5 & 0.5 & 6.2 \\
\hline & Copepoda & 48 & 21.2 & 13.6 & 4.6 & 0.2 & 4.1 \\
\hline & Cladocera & 24 & 10.6 & 4.1 & 1.4 & 0.03 & 2.0 \\
\hline
\end{tabular}




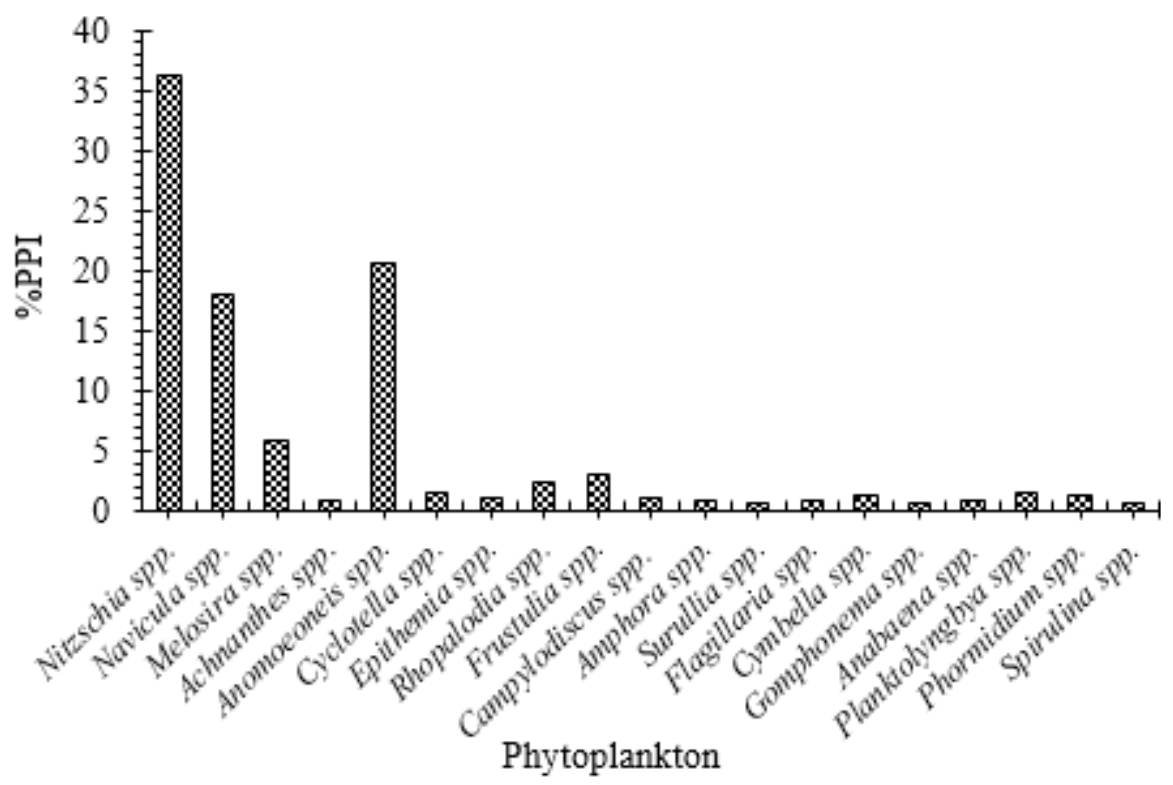

Fig. 3. Phytoplankton preference index of Oreochromis niloticus in Lake Shala from January to December 2018.

(Fig. 4). Their volumetric contribution was $48.9 \%$ of the total food items. In addition to zooplankton as the main prey item, other important food resources for smaller-sized fish $(<15$ $\mathrm{cm}$ ) were phytoplankton and accounted for $24.6 \%$ of the total volume of food items. Insect (Chironomidae) was another food source of animal origin relatively important in the diet. Their volumetric contribution was $18.9 \%$ of the food items in this specific size class. However, the volumetric contribution of zooplankton, insect and detritus decreased considerably as the fish size increased.

The volumetric contribution of phytoplankton showed significant variation among the different size classes (ANOVA, $p<$ 0.05 ). The volumetric contribution of phytoplankton showed an increasing trend with fish size. In the intermediate and largest size class $15-20,20-25,25-30$ and $>30 \mathrm{~cm}$ TL, the contribution of phytoplankton was $64.8 \%, 85.9 \%, 98.9 \%$, and $100 \%$ of the total volume of food items, respectively. While the contributions of other foods of animal origin such as zooplankton and insects were insignificant (ANOVA, $p>0.05$ ).

\section{Seasonal variation in the diet of O. niloticus in Lake Shala}

The seasonal contribution of different food items in the stomach of $O$. niloticus is shown in Table 3. The result clearly exhibits seasonal variations in the diet composition of the fish in Lake Shala. Phytoplankton was the most important food item during both the dry and wet seasons. However, phytoplankton showed a significant variation in the dietary contribution of $O$. niloticus ( $t$-test, $p<0.05)$ and significant during the dry months. During the dry season, phytoplanktons occurred in $94.7 \%$ of the stomachs and comprising $84.9 \%$ of the total volume of food items. However, its contribution decreased to $60.3 \%$ of the total volume during the wet season.

Zooplankton also showed a seasonal variation in the diet composition of $O$. niloticus and significant during the wet season. Zooplankton was observed in $54.3 \%$ of the stomach contents and comprised $21.4 \%$ of the total volume of the food during the wet season. But their contribution declined during the dry season (27.3\%) and accounted for $10.3 \%$ of the total volume of food items. Insect (Chironomids), nematode, fish scales and detritus also demonstrated significant seasonal variations in the diet of $O$. niloticus and it was important during the wet season.

\section{Discussion}

\section{Diet composition and feeding habits of 0 . niloticus}

The stomach content analysis showed that 117 (34.1\%) of the stomachs were empty while 226 (65.9\%) contained varied quantity of food. This high number of empty stomachs may be attributed the post-harvest digestion or the method of catching of the specimens. Oso et al. (2006) and Engdaw et al. (2013) also reported an empty stomachs for O. niloticus, caught with 


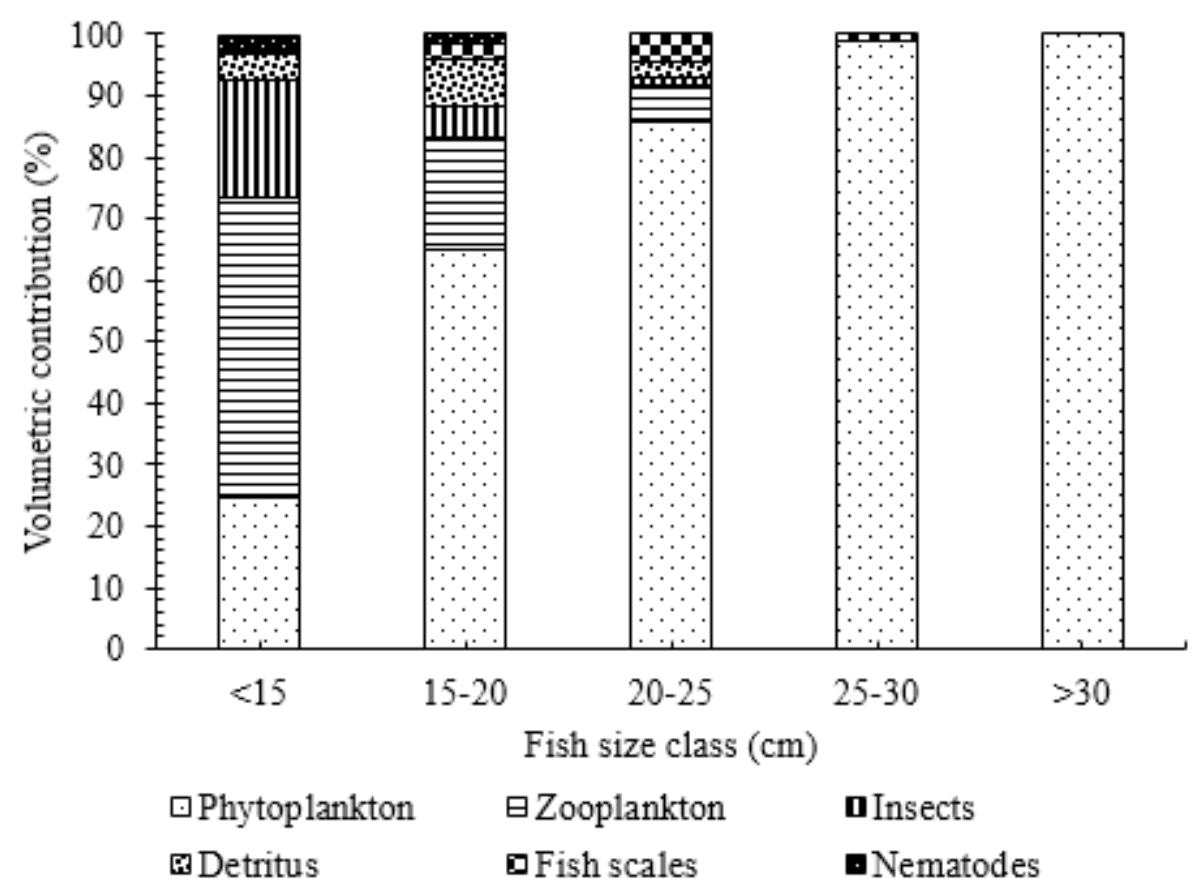

Fig. 4. Volumetric contributions of different food items in the diet of different size classes of Oreochromis niloticus in Lake Shala, Ethiopia.

Table 3. Relative contribution percentage frequency of occurrence (\%Qi), volumetric contribution $(\% \mathrm{Vi})$, index of preponderance (\%IOP) and geometric index of importance (\%GIli) of different food items in the diet of Oreochromis niloticus in Lake Shala during the dry and wet seasons

\begin{tabular}{|c|c|c|c|c|c|c|c|c|}
\hline \multirow[t]{2}{*}{ Food type } & \multicolumn{2}{|l|}{$\% O \mathrm{i}$} & \multicolumn{2}{|l|}{$\% \mathrm{Vi}$} & \multicolumn{2}{|c|}{ IOP\% } & \multicolumn{2}{|c|}{ (\%Glli) } \\
\hline & Dry & Wet & Dry & Wet & Dry & Wet & Dry & Wet \\
\hline Phytoplankton & 94.7 & 84.0 & 84.9 & 60.3 & 96.2 & 77.4 & 65.8 & 47.4 \\
\hline Zooplankton & 27.3 & 54.3 & 10.3 & 21.4 & 3.4 & 17.7 & 13.8 & 24.9 \\
\hline Insects & 9.1 & 16.0 & 3.0 & 8.5 & 0.3 & 2.1 & 4.4 & 8.0 \\
\hline Nematodes & 7.6 & 14.9 & 0.4 & 1.4 & 0.04 & 0.3 & 2.9 & 5.4 \\
\hline Fish scales & 5.3 & 11.7 & 0.9 & 2.6 & 0.06 & 0.5 & 2.3 & 4.7 \\
\hline Detritus & 6.8 & 23.4 & 0.4 & 5.8 & 0.04 & 2.1 & 2.7 & 9.6 \\
\hline
\end{tabular}

gill nets in Ero and Koka reservoir. The reason for this may be due to the fact that the food items in their stomach may have been regurgitated or digested as the fish struggled for escape in gill nets during the catches. The present study found a variety of food items of phytoplankton, zooplankton, insects, nematodes, fish scales, and detritus in the stomachs of O. niloticus. This did not differ from the findings of Adeyemi et al. (2009) and Kuebutornye et al. (2019) which reported O. niloticus have varying food including plant and animal origin in its gut. Many authors have also reported in different Ethiopian water bodies that $O$. niloticus feeds on a variety of food items (Assefa \& Getahun, 2015; Engdaw et al., 2013; Teferi et al., 2000; Temesgen, 2017; Wakjira, 2013).

Phytoplankton was the most important food item in all stomach of O. niloticus in Lake Shala. This indicated that the fish was a phytoplanktivorous or herbivorous feeder. These findings are supported well by earlier findings that have classified $O$. niloticus as herbivorous that favor phytoplankton species (Abdulhakim et al., 2015; Engdaw et al., 2013; Hussian et al., 2019; Teferi et al., 2000). Phytoplanktivorous or herbivorous feeding habits of $O$. niloticus have also been reported in Ethiopian water bodies such as Lake Chamo (Teferi et al., 2000), Koka Reservoir (Engdaw et al., 2013) and Lake Hayq (Assefa \& Getahun, 2015). However, this result was in disagreement with Oso et al. (2006), who suggested that $O$. niloticus has omnivorous feeding habits. The contrasting feeding habits of the fish may be due to the differences in the abundance of food items in different locations.

In the present study, O. niloticus preferred Bacillariophyceae (diatoms) than the phytoplankton groups. These findings were supported by the work of Abdulhakim et al. (2015), Temesgen (2017), and Hussian et al. (2019) who mentioned that Bacillariophyceae were the most prevailing food items and 
highly desired by O. niloticus. The study of Kariman et al. (2009) also pointed out that the diatoms are the most important food items than any food items and represented about $68.0 \%$ from the total gut content of O. niloticus in Abu-Zabal Lake, Egypt. However, the dominance of green algae in Lake Hawassa (Tudorancea et al., 1988), blue-green algae in Lake Zeway (Tadesse, 1988), Hayq (Assefa \& Getahun, 2015) and Koka Reservoir (Engdaw et al., 2013) were reported in the food composition of the same fish. These differences could be related to variations in environmental and biological factors among the lakes which influence the types of food items ingested by the fish (Bwanika et al., 2004; Temesgen, 2017). According to Kebede \& Willén (1996) the diatoms had a higher percentage abundance than the blue-green algae in Lake Shala. Besides, these diatoms are highly digestible because the holes in the frustules permit the entry of enzyme into the cytoplasm to enhance digestion (Harbott, 1975; Teferi et al., 2000). This means that O. niloticus in Lake Shala was selecting diatoms more than other groups of algae.

Apart from the major food items, they also picked a variety of other food items including rotifers, copepods, and Chironomidae, which contributed an appreciable amount in the food composition of $O$. niloticus in Lake Shala due to some nutritional benefits. Several authors have provided similar interpretations about the importance of zooplankton and insects in the diet of O. niloticus in different lakes and reservoirs (Abdulhakim et al., 2015; Adeyemi et al., 2015; Assefa \& Getahun, 2015; Engdaw et al., 2013; Teferi et al., 2000; Temesgen, 2017).

\section{Diet composition in relation to fish size}

Oreochromis niloticus have been known to feed on a wide variety of items such as phytoplankton, detritus, plant material, chironomids and zooplankton (Kuebutornye et al., 2019; Oso et al., 2006; Tomojiri et al., 2019). Its feeding habits of may be varying according to size (Temesgen, 2017; Tomojiri et al., 2019). In the present study, O. niloticus showed size-based differences in their feeding habit. The main prey items were phytoplankton in the larger-size class, but smaller size fish tended to consume various aquatic animals and planktons, such as zooplankton, insects and phytoplankton. This showed that juveniles of $O$. niloticus are generally omnivorous in their feeding style. This did not differ markedly from Temesgen (2017), who suggested O. niloticus as omnivorous feeding on both animal and plant origin at juvenile size class. However, this was in contrast with Teferi et al. (2000) and Engdaw et al. (2013), who reported that O. niloticus had a preference for food items of animal origin (zooplankton and insects) at juvenile stages.

The study showed that adult O. niloticus fed more on phytoplankton than other food items. This suggested that $O$. niloticus in Lake Shala switched their primary food resource in favor of phytoplankton. This finding agreed with Hussian et al. (2019) and Engdaw et al. (2013), who reported O. niloticus was phytoplanktivore in its feeding habit at a larger size. Similarly, the findings from the current study also agreed with the work of Teferi et al. (2000), who reported phytoplankton as a major item in the diet of adult $O$. niloticus in Lake Chamo. This size based difference in feeding habits of $O$. niloticus may be due to energy demands, development of the fish's morphological and physiological features as it grows (Abdulhakim et al., 2015; Njiru, 2004). Also, the life history of O. niloticus is diverse (Bwanika et al., 2004; Nyakuni, 2009), depending on the habitat they used, and its food habits can vary widely (Assefa \& Getahun, 2015; Engdaw et al., 2013; Tadesse, 1988; Teferi et al., 2000).

\section{Seasonal variation in the diet of $O$. niloticus in Lake Shala}

During the studies of fish feeding, the effect of seasonality should always be considered, because the seasonal changes of biotic and abiotic factors alters the structure of the food web along the year and, as a consequence, the fish often shows seasonal diet shifts (Kariman et al., 2009). In the current study, the food items of O. niloticus in Lake Shala showed a significant seasonal variation. Some previous studies also found a seasonal variation of food types in the diet composition of $O$. niloticus in the Ethiopian water bodies (Assefa \& Getahun, 2015; Engdaw et al., 2013; Teferi et al., 2000; Temesgen, 2017). The volumetric contribution of phytoplankton was higher during the dry than a wet season and is consistent with the study of Temesgen (2017) and Assefa \& Getahun (2015) who indicated that phytoplankton is the most important food item consumed during the dry season. However, this finding was in contrast to that recorded by Wakjira (2013), who found a higher contribution of phytoplankton in the diet of $O$. niloticus during the wet season in Gilgel Gibe I Reservoir, Ethiopia.

The results from this study showed that the contribution of zooplankton, insect, detritus, nematodes, and fish scales was higher during the wet season. This was similar to earlier reports for these fish species in some other water bodies (Assefa \& Getahun, 2015; Engdaw et al., 2013; Temesgen, 2017; Wakjira, 2013). The proportion of zooplankton in the diet of O. niloticus was higher during the wet season, might be related with seasonal flooding which contribute to the high zooplankton 
population through bringing nutrients from the catchments which support the growth of phytoplankton and consequently zooplankton productivity (Temesgen, 2017). This corroborates the reports of Assefa \& Getahun (2015) and Engdaw et al. (2013) in Lake Hayq and Koka Reservoir, respectively.

The contribution of detritus was higher in the diet of $O$. niloticus during the wet season. This may be due to flooding which brings dead plant and animal parts into the lake and undergo partial decomposition. The dominance of detritus in the diet during the rainy season was consistent with the study by Temesgen (2017) in Lake Langeno and Engdaw et al. (2013) in Koka Reservoir. Similarly, the high contribution of insects in the diet composition of $O$. niloticus during the wet season may be associated with the reproductive biology of the fish (Kebede et al., 2018). Fish activities to shallow parts of the lake and remaining there for reproduction could be an explanation to the increase in ingested insects in the wet season (Assefa \& Getahun, 2015; Temesgen, 2017; Wakjira, 2013). This is quite similar to the findings of other investigators in the Ethiopian rift valley lakes (Engdaw et al., 2013; Tadesse, 1988; Temesgen, 2017).

\section{Conclusion}

This study shows the importance of phytoplankton as food items and O. niloticus is primarily phytoplanktivores in Lake Shala. They fed mainly on Bacillariophyceae than any other group of phytoplankton. However, the feeding habit and diet composition varied according to size, the juvenile O. niloticus is an omnivores, feeding on diverse aquatic animals and planktons, such as zooplankton, insects and phytoplankton while the adult is phytoplanktivores feeding mainly on phytoplankton. The diet composition of O. niloticus also differed among the studied seasons. The main prey items were phytoplankton during the dry season and the contribution of zooplankton, insect, detritus, nematodes, and fish scales was higher during the wet season. Therefore, it could be concluded that food items and feeding habits depending on availability as influenced by season and fish size $O$. niloticus in Lake Shala.

\section{Competing interests}

No potential conflict of interest relevant to this article was reported.

\section{Funding sources}

We appreciate the financial support provided by Addis Ababa
University through its Graduate Studies Program and Thematic Research Project.

\section{Acknowledgements}

We thank Dr. Assefa Wosnie and Dr. Yirga Enawgaw for their help and advice in fieldwork and research techniques. Finally, we thank the Ethiopian Wildlife Conservation Authority (EWCA) and Abijatta-Shala Lakes National Park Administration for granting permission to conduct research in Lake Shala.

\section{Availability of data and materials}

Upon reasonable request, the datasets of this study can be available from the corresponding author.

\section{Ethics approval and consent to participate}

This article does not require IRB/IACUC approval because there are no human and animal participants.

\section{ORCID}

Solomon Wagaw https://orcid.org/0000-0001-6656-3832

Seyoum Mengistou https://orcid.org/0000-0003-3530-8016

Abebe Getahun https://orcid.org/0000-0003-4489-3907

\section{References}

Abdi M. Impact of human activity on Abijata-Shalla Lakes National Park ecosystem [Ph.D. dissertation]. Oslo: Agricultural University of Norway; 1993.

Abdulhakim A, Addo S, Lawan ZA, Ebenezer A. Feeding habits and condition factor of Oreochromis niloticus in Lake Alau, Northeastern Nigeria. Algae. 2015;32:23-36.

Adeyemi SO, Akombu PM, Toluhi OO. Food and feeding habits of Oreochromis niloticus in Lake Gbedikere, Bassa, Kogi state. Cont J Anim Vet Res. 2009;1:25-30.

Assefa WW, Getahun A. The food and feeding ecology of Nile tilapia, Oreochromis niloticus, in Lake Hayq, Ethiopia. Int J Ecol Environ Sci. 2015;41:55-65.

Assis CA. A generalised index for stomach contents analysis in fish. Sci Mar. 1996;60:385-9.

Ayenew T, Legesse D. The changing face of the Ethiopian Rift lakes and their environs: call of the time. Lake Reserv Res Manag. 2007;12:149-65.

Baumann A, Förstner U, Rohde R. Lake Shala: water chemistry, mineralogy and geochemistry of sediments in an Ethiopian Rift lake. Geol Rundsch. 1975;64:593-609. 
Baxter RM. Lake morphology and chemistry. In: Taylor WD, Tudorancea C, editors. Ethiopian Rift valley lakes. Leiden: Backhuys; 2002.

Bellinger EG, Sigee DC. Introduction to freshwater algae: identification and use as bioindicators. Hoboken, NJ: Wiley-Blackwell; 2010.

Bwanika GN, Makanga B, Kizito Y, Chapman LJ, Balirwa J. Observations on the biology of Nile tilapia, Oreochromis niloticus L., in two Ugandan Crater lakes. Afr J Ecol. 2004;42:93101.

Chrisafi E, Kaspiris P, Katselis G. Feeding habits of sand smelt (Atherina boyeri, Risso 1810) in Trichonis Lake (western Greece). J Appl Ichthyol. 2007;23:209-14.

Defaye D. Contribution a la connaissance des Crustaces Copepodes d'Ethiopie. Hydrobiologia. 1988;164:103-47.

Engdaw F, Dadebo E, Nagappan R. Morphometric relationships and feeding habits of Nile tilapia Oreochromis niloticus (L.) (Pisces: Cichlidae) from Lake Koka, Ethiopia. Int J Fish Aquat Sci. 2013;2:56-71.

Gasse F, Talling JF, Kilham P. Diatom assemblages in East Africa: classification, distribution and ecology. Rev Hydrobiol Trop. 1983;16:3-4.

Gebremariam Z. The Ethiopian Rift valley lakes: major threats and strategies for conservation. In: Tudorancea C, Taylor WD, editors. Ethiopian Rift Valley Lakes. Euro: Net; 2002. p. 259-71.

Getahun A. Lake Afdera: a threatened saline lake in Ethiopia. SINET: Ethiop J Sci. 2001;24:127-31.

Golubtsov AS, Dgebuadze YY, Mina MV. Fishes of the Ethiopian Rift valley. Ethiop Rift Valley Lakes. 2002;167:258.

Harbott BJ. Preliminary observation on the feeding of Tilapia niloticus Linn. In Lake Rudolf. Afr J Trop Hydrobiol Fish. 1975;12:71-81.

Hussian AEM, Aly W, Morsi HH. Feeding on phytoplankton profile of two African Cichlids in large reservoir, Lake Nasser, Egypt. Egypt J Aquat Biol Fish. 2019;23:451-64.

Hyslop EJ. Stomach contents analysis: a review of methods and their application. J Fish Biol. 1980;17:411-29.

Kariman A, Shalloof S, Khalifa N. Stomach contents and feeding habits of Oreochromis niloticus (L.) from Abu-Zabal Lakes, Egypt. World Appl Sci. 2009;6:1-5.

Kavembe GD, Meyer A, Wood CM. Fish populations in East African saline lakes. In: Schagerl M, editor. Soda lakes of East Africa. Cham: Springer; 2016. p. 227-57.

Kebede MT, Getahun A, Lemma B. Reproductive biology of commercially important fish species in Lake Langeno, Ethiopia. Asian Fish Sci. 2018;31:319-39.

Kebede E, Willén E. Phytoplankton in a salinity-alkalinity series of lakes in the Ethiopian Rift valley [Ph.D. dissertation]. Uppsala: Uppsala University; 1996.

Kebede E, Mariam ZG, Ahlgren I. The Ethiopian Rift valley lakes: chemical characteristics of a salinity-alkalinity series. Hydrobiologia. 1994;288:1-12.

Klemperer SL, Cash MD. Temporal geochemical variation in Ethiopian Lakes Shala, Arenguade, Awasa, and Beseka: possible environmental impacts from underwater and borehole detonations. J Afr Earth Sci. 2007;48:174-98.

Kuebutornye FKA, Akongyuure DN, Alhassan EH. Morphometric characteristics and feeding habits of five commercial fish species of the Libga reservoir in the northern region of Ghana. Int J Oceanogr Aquac. 2019;3:000164.

Le Turdu C, Tiercelin JJ, Gibert E, Travi Y, Lezzar KE, Richert JP, et al. The Ziway-Shala lake basin system, main Ethiopian Rift: influence of volcanism, tectonics, and climatic forcing on basin formation and sedimentation. Palaeogeogr Palaeoclimatol Palaeoecol. 1999;150:135-77.

Njiru M, Okeyo-Owuor JB, Muchiri M, Cowx IG. Shifts in the food of Nile tilapia, Oreochromis niloticus (L.) in Lake Victoria, Kenya. Afr J Ecol. 2004;42:163-70.

Nyakuni L. Habitat utilization and reproductive biology of Nile tilapia (Oreochromis niloticus) in Albert Nile, Nebbi district. Makerere University; 2009.

Ogato T. Dynamics of phytoplankton and physicochemical features of the Ethiopian soda lakes Chitu and Shala, and evaluation of the potential of their waters for the production of Arthrospira (Spirulina) fusiformis (Cyanophyceae) in laboratory cultures [Ph.D. dissertation]. Addis Ababa: Addis Ababa University; 2015.

Oso JA, Ayodele IA, Fagbuaro O. Food and feeding habits of Oreochromis niloticus (L.) and Sarotherodon galilaeus (L.) in a tropical reservoir. World J Zool. 2006;1:118-21.

Reaugh-Flower K. Abijata-Shalla Lakes National Park: assessment of factors driving environmental change for management decision-making. Addis Ababa, Ethiopia: Ethiopian Wildlife Conservation Authority; 2011.

Sreeraj N, Raghavan R, Prasad G. The diet of Horabagrus brachysoma (Gunther), an endangered bagrid catfish from Lake Vembanad (South India). J Fish Biol. 2006;69:637-42.

Tadesse Z. Studies on some aspects of the biology of Oreochromis niloticus Linn (Pisces: Cichilidae) in Lake Ziway Ethi- 
opia [M.S. thesis]. Addis Ababa: Addis Ababa University; 1988. p. 78.

Teferi Y, Admassu D, Mengistou S. The food and feeding habit of Oreochromis niloticus L. (Pisces: Cichlidae) in Lake Chamo, Ethiopia. SINET: Ethiop J Sci. 2000;23:1-12.

Temesgen M. Status and trends of fish and fisheries in Lake Langeno, Ethiopia [Ph.D. dissertation]. Addis Ababa: Addis Ababa University; 2017.

Tomojiri D, Musikasinthorn P, Iwata A. Food habits of three non-native cichlid fishes in the lowermost Chao Phraya river basin, Thailand. J Freshw Ecol. 2019;34:419-32.

Tudorancea C, Fernando CH, Paggi JC. Food and feeding ecology of Oreochromis niloticus (Linnaeus, 1758) juveniles in Lake Hawassa (Ethiopia). Arch Hydrobiol Supply. 1988;79:267-89.

Von Damm KL, Edmond JM. Reverse weathering in the closed-basin lakes of the Ethiopian Rift. Am J Sci. 1984;284:835-62.

Wakjira M. Feeding habits and some biological aspects of fish species in Gilgel Gibe reservoir, Ethiopia. Int J Curr Res. 2013;5:4124-32. 